\title{
EVALVACIJA ODNOSOV Z JAVNOSTMI V SLOVENSKI VOJSKI
}

\section{EVALUATION OF SLOVENIAN ARMED FORCES PUBLIC AFFAIRS}

Povzetek Kakovostni odnosi z javnostmi so pomembni za delovanje in legitimnost oboroženih sil. Podatek o zaupanju javnosti v oborožene sile je pomembna povratna informacija vsem zaposlenim v njih in motivacija za nadaljnje delo.

V prispevku je predstavljena evalvacija odnosov z javnostmi v Slovenski vojski. Opravljena je bila znotraj štirih različnih projektov in je trajala od aprila 2010 do julija 2013. Namen evalvacije je bil ugotoviti, kako kakovostno je področje dela odnosov z javnostmi v Slovenski vojski. V evalvacijo so bile vključene različne javnosti, notranjo so predstavljali vzorci vojakov, podčastnikov in častnikov, zunanjo pa predstavniki slovenskih medijev ter strokovnjaki in akademiki, specializirani za področje odnosov z javnostmi.

Ključne Odnosi z javnostmi, evalvacija, oborožene sile, Slovenska vojska, javno mnenje, besede javno zaupanje.

Abstract Quality public affairs are important for the functioning and legitimacy of the armed forces. Data on public trust in the armed forces are an important feedback to all employees and their motivation for further work.

The paper presents an evaluation of public affairs in the Slovenian Armed Forces. It has been carried out within four different projects from April 2010 to July 2013. The aim of the evaluation was to determine the quality of public affairs in the Slovenian Armed Forces. The evaluation included different publics; the internal public represented by soldiers, NCOs and officers, and the external public represented by Slovenian and foreign media representatives, as well as experts and scholars specializing in the field of public relations.

Key words Public affairs, evaluation, armed forces, Slovenian Armed Forces, public opinion, public trust. 
Uvod Slovenska vojska (SV) po raziskavah Centra za raziskovanje javnega mnenja (CJM) dosega od osamosvojitve Slovenije razmeroma visoke uvrstitve na lestvici zaupanja slovenske javnosti v javne institucije. Zaupanje javnosti v vojsko kot državno institucijo je velikega pomena in neposredno povezano z razmerami za njeno delovanje. Splošna javnost in javni politični odločevalci sta tisti ciljni javnosti, ki lahko vplivata, politični odločevalci pa tudi odločajo o poslanstvu, delovanju, financiranju in prihodnosti oboroženih sil. Vse to vpliva na kakovost delovanja, ki pa je v primerjavi z zunanjimi javnostmi odvisno tudi od notranje ali interne javnosti v oboroženih silah. Notranjo ali notranje javnosti v obrambnem sistemu predstavljajo vsi zaposleni, z različnimi statusi, kot na primer civilne (uradniki, strokovno-tehnični delavci) in vojaške osebe (vojaki, podčastniki, častniki in generali ter vojaški uslužbenci) v različnih notranjih organizacijskih enotah, poudarek v tem članku pa bo na zaposlenih v vojski.

Zaupanje javnosti v državne institucije je pomembno z vidika delovanja države. Ta v demokratičnih družbah želi delovati javno, pregledno in v sodelovanju s civilno družbo, in sicer z namenom doseči najboljše učinke pri opravljanju svojega poslanstva. Oborožene sile spadajo med represivne državne organe, ki svoje poslanstvo opravljajo zelo drugače kot druge državne institucije. Ta posebnost se kaže tudi v uporabi orožja in delovanju zunaj državnih meja v mednarodnih operacijah in na misijah v varnostno tveganih okoljih in razmerah. To pomeni večjo odgovornost za politične odločevalce, ki o takih napotitvah odločajo, hkrati pa tudi za zaposlene v oboroženih silah, ki morajo biti dodatno usposobljeni in opremljeni zaradi morebitne večje nevarnosti pri opravljanju njihovega poslanstva. Pri vsem tem imajo pomembno vlogo odnosi z javnostmi, ki veliko prispevajo k obveščenosti javnosti o delovanju oboroženih sil in hkrati k zaupanju vanje.

Kako kakovostno je področje dela odnosov z javnostmi v SV?

Iz zaupanja slovenske javnosti v javne institucije lahko na primeru SV sklepamo, da tako vojska kot zaposleni v njej dobro opravljajo svoje poslanstvo. Po podatkih CJM celo zelo dobro, saj je stopnja zaupanja v SV sorazmerno stalna glede na to, da se zaupanje v druge javne institucije v primerjavi s SV zmanjšuje. Za javno podobo SV strokovno skrbijo zaposleni na področju odnosov z javnostmi ${ }^{1}$. Meritve slovenskega javnega mnenja so samo eden izmed pokazateljev zunanje kakovosti delovanja odnosov z javnostmi v vojski, zato smo želeli preveriti tudi druge načine ocenjevanja kakovosti tega področja, na primer notranjo javnost in predstavnike medijev, pri čemer smo uporabili metodo evalvacije.

Na javno podobo SV in s tem na zaupanje javnosti vpliva vsak posameznik s svojo fizično pojavo in svojim delovanjem tako v službi kot v prostem času. 


\section{TEORETIČNA IZHODIŠČA, POMEMBNA ZA EVALVACIJO}

\subsection{Odnosi z javnostmi}

Pojem odnosi z javnostmi (Public Relations) je rezultat dela Edwarda L. Bernaysa ${ }^{2}$, ki se je oprl na dve deli iz 19. stoletja, avtorjev Dormana B. Eatona ${ }^{3}$ (1882) in Hougha Smitha ${ }^{4}$ (1842), ki sta takrat pisala o javnih odnosih, pozneje pa se je pojem postopoma preoblikoval $\mathrm{v}$ odnose $\mathrm{z}$ javnostmi. Bernays sam je zapisal, da odnosi z javnostmi pomenijo natančno to, kar piše, odnose organizacije, posameznika, ideje ali česar koli že z javnostmi, od katerih je odvisen njihov obstoj (Bernays, 1986, str. 35, v Verčič, 1995, str. 17).

Hallahan razume odnose z javnostmi kot eno izmed šestih disciplin, ki sestavljajo koncept komunikacijskega menedžmenta, hkrati pa poudarja, da imajo posamezne komunikacijske discipline skupen namen, njihovi cilji in strategije pa so si zelo podobni. Razlikujejo se predvsem v taktiki, željah organizacij po usklajevanju komuniciranja, konvergenci medijev in zabrisovanju meja med komunikacijskimi zvrstmi, ki jih silijo k prilagajanju spreminjajočemu se okolju. Nadaljuje, da organizacije stremijo $\mathrm{k}$ integraciji in večji uspešnosti predvsem s sinergijo in boljšo učinkovitostjo ter manj s tehnološkimi presežki (Hallahan in dr., 2008, str. 630). Poleg odnosov z javnostmi so druge discipline še upravljavsko (menedžersko), tržno, strokovno in politično komuniciranje ter informativne oziroma družbene kampanje (prav tam).

Mednarodno združenje za odnose z javnostjo je opredelilo te odnose kot $\gg / . . . /$ veščino in družbeno vedo o analiziranju trendov, napovedovanju njihovih posledic, svetovanju organizacijskim vodjem in izvajanju načrtovanih programov dejanj $\mathrm{v}$ interesu skupnosti in javnosti.« (Verčič, 1999, str. 520-521)

Tiskovni predstavnik SV Simon Korez pravi: »Če želimo uresničevati poslanstvo stroke, kot ga opredeljuje ena od številnih definicij, je treba odnose z javnostjo voditi na strateški način, s pomočjo pretehtanega načrtovanja, pozornega vodenja dejavnosti ter stalnega raziskovanja in vrednotenja učinkov komuniciranja. Odločanje za posamične in ad hoc dejavnosti ne more zagotoviti uspešnega in učinkovitega komuniciranja.« (Korez, 2008, str. 58)

Kot nadaljuje Korez, je razumevanje odnosov z javnostmi povezano predvsem z doseganjem publicitete $\mathrm{v}$ medijih in to za vsako ceno. Odnosi z mediji kot posredovalci in tudi oblikovalci sporočanja so pomembno področje delovanja, nikakor pa ne edino.

\footnotetext{
Edward Luis Bernays (1891-1995), rojen v Avstriji, živel v ZDA. Velja za »očeta odnosov z javnostmi«.Združil je ugotovitve na področju psihologije množic in psihoanalizo svojega strica Sigmunda Freuda. Po oceni revije Life magazine velja za eno od stotih najvplivnejših oseb 20. stoletja.

3 Avtor knjige The public Realtions and Duties othe Legal Proffession.

4 Avtor knjige The Theory and Regulation of Pubic Setiment.
} 
Tako komunikacijske dejavnosti niso same sebi namen. Komunikatorji jih vodijo predvsem v podporo doseganju organizacijskih poslovnih ciljev. »V vojaški skupnosti so to naslednji cilji: pozitivna javna podoba Slovenske vojske, pozitivna, vendar realna promocija vojaškega poklica (v vojaški skupnosti ne sme biti propagande), podpora poveljnikom pri sprejemanju odločitev za ukrepe pri vodenju in poveljevanju ter priprava in vodenje komunikacijskih strategij za podporo projektom.« (prav tam)

\subsection{Evalvacija na področju odnosov $\mathrm{z}$ javnostmi}

Beseda evalvacija v slovenskem jeziku pomeni ocenjevanje, vrednotenje, slovar angleškega jezika pa jo pojasnjuje tudi kot preračunavanje, določitev vrednosti. V literaturi se pojavlja tudi zapis evaluacija, vendar je zelo redek.

Paton pravi, da je vrednotenje sistemsko zbiranje, analiziranje in ocenjevanje informacij o aktivnostih, značilnostih in rezultatih programov, da bi tako zmanjšali negotovost, povečali uspešnost ter oblikovali odločitve skladno s cilji in nameni programov (1986).

Razlika med vrednotenjem in raziskovanjem je po Bennetovi (2003, str. 14) v tem, da je raziskovanje usmerjeno $\mathrm{v}$ razumevanje pojava, ki ga raziskuje, vrednotenje pa $\mathrm{v}$ odkrivanje vrednosti in koristi nekega projekta. Bennetova razume raziskovanje kot ožje usmerjeno, pri čemer je pomembna strokovna veljavnost, vrednotenje pa kot bolj celovito, pri čemer sta pomembni uporabnost in verodostojnost. Kot pravi Serajnikova, rezultati vrednotenja na področju odnosov z javnostmi prispevajo $\mathrm{k}$ spremembam - na bolje ali na slabše (opustitev programa oziroma dela), odprejo se kritična vprašanja in poveča se občutljivost vpletenih (2008, str. 850).

V povezavi z evalvacijo na področju odnosov z javnostmi loči Rühl tri pristope: laičnega, strokovnega (profesionalnega) in akademskega. Pri laičnem se praktiki zanašajo na zdravo presojo. Delujejo, presojajo in ocenjujejo na podlagi svojih izkušenj in občutkov. Strokovnjaki prisegajo na profesionalne formalne (zakoni, kodeksi, standardi itn.) ter neformalne norme (morala, zaupanje, odgovornost itn.), ki jih postavljajo in negujejo organizacije. Merjenja in vrednotenja se organizirano lotevajo nacionalna in mednarodna združenja. Akademska skupnost loči med aplikativnim in znanstvenim raziskovanjem. Prvo si prizadeva najti praktične rešitve za strateško načrtovanje in delovanje, usmerjeno pa je na področje poklicne prakse odnosov z javnostmi, v oblikovanje oblik ter načinov konceptualizacije in uveljavitve komunikacijskega menedžmenta za doseganje uspešnosti in učinkovitosti. Znanstvenega raziskovanja je bistveno manj (Rühl, 2008, str. 21).

Ključno vprašanje pri tem pa je, kaj odnosi z javnostmi prispevajo družbeno, organizacijsko, funkcionalno, programsko, projektno in individualno. Da bi vse našteto ugotovili, je nujno raziskovanje odnosov z javnostmi. Rühlov članek ${ }^{5}$ tremi pristopi

Članek Public relations methodology Should we bother (If it exists)? v monografiji avtorjev Betteke, Tkalac

Verčič in Verčič z naslovom Public relations metrics: Research and evaluations. 
k evalvaciji odnosov z javnostmi nam je bil vodilo pri evalvaciji v SV. V njem pravi, da je sociološki pogled na upravljanje odnosov z javnostmi kot funkcionalnega sistema predvsem v spodbujanju in ohranjanju javnega interesa in javnega zaupanja. Zunanji vidik odnose $\mathrm{z}$ javnostmi pokaže kot sistem vsakodnevnega prepričevanja javnosti, medtem ko notranji vidik lahko razumemo dvojno, kot prakso stroke in kot podpodročje komuniciranja s svojim raziskovanjem in teoretičnimi podlagami (Rühl, 2008, str. 21). Odnosov z javnostmi tako ne moremo vrednotiti v finančnem smislu, saj so njihovi ključni rezultati pozornost javnosti, strokovno delo, moralna načela, smiselnost informacij, spodbujanje novih tem, uravnoteženost zakonodaje ter zaupanje javnosti in posameznikov (prav tam).

\subsubsection{Javno mnenje kot eden izmed kazalnikov kakovosti odnosov z javnostmi v oboroženih silah}

Javno mnenje je najsplošnejši izraz mnenj, stališč in razpoloženj javnosti o vprašanjih splošnega interesa, pravita Rus in Toš. Javno mnenje je le končni izraz, večinska ali kolektivna sodba, ki jo v mnenjskem procesu poda javnost in je družbeno determinirana. Kot pravita avtorja, gre za posledico dinamičnega in protislovnega mnenjskega procesa v temeljni skupnostni ravnini, ki pa se v nadaljnjem mnenjskem procesu modificira ali celo spremeni (2005, str. 336-369).

Spremembe, ki so vplivale na mednarodno varnostno okolje po koncu hladne vojne in 11. septembru 2001, se kažejo tudi na oboroženih silah in njihovih odnosih z javnostmi. Postmoderno sodobno vojsko zaznamuje vse večja odprtost vojaških organizacij v komuniciranju z javnostmi, v izmenjavi informacij in dostopnosti do njih, v večji lastni medijski produkciji ter pripravljenosti za sodelovanje z množičnimi mediji (prav tam).

Na preobrazbo v komuniciranju vojaške sfere so pomembno vplivali zlasti:

- opuščanje obvezniškega popolnjevanja in prehod na (popolnoma) poklicno vojsko;

- vpliv globalizacije in sodobnih komunikacijskih tehnologij;

- proces demokratizacije in spreminjanja vrednot, naraščajoči pomen človekovih pravic te preprečevanje kritičnih zahtev javnosti (Van Dyke, Verčič, 2009).

Teoretični okvir za raziskovanje vloge oboroženih sil v odnosu do javnosti je $\mathrm{v}$ prejšnjem stoletju postavil Huntington, pozneje pa so ga pomembno nadgradili Edmonds, Jelušičeva in drugi. Bistvo njegove teze je, da se vojske kot družbene institucije lahko ohranjajo le, »/.../ če izpolnjujejo imperative javnosti« (Huntington, 1957). Oborožene sile in obrambni sistemi $» / \ldots /$ se morajo prilagajati zahtevam javnosti, vendar pa te zahteve predhodno sooblikujejo s poseganjem v proces oblikovanja javnega mnenja /.../« meni Prezelj (1997, str. 1020). Z vidika javnosti in medijev se zastavlja vprašanje ravnotežja med izpolnjevanjem socialnega in funkcionalnega imperativa. Slednji predstavlja temeljno poslanstvo vojske - torej obrambo države v razmerju do socialnega imperativa, ki je »/.../ rezultat ideologij, vrednot in kulturnih norm« (Jelušič, 1997, str. 68). 
Prezelj pa pravi, da »/.../ bolj kot se zdi, da vojska deluje v duhu postavljenih zahtev, bolj je sprejemljiva za javnost v celoti in tudi za posebne javnosti. Sprejemljivost določene državne institucije pa je pogoj za doseganje lojalnosti državljanov in za priznanje legitimnosti /.../« (Prezelj, 1997, str. 21). Kot pravi Jelušičeva, je legitimnost varnostne politike in oboroženih sil v demokratično oblikovani družbi izpostavljena neprestanemu preverjanju in vplivanju. Legitimnost ni nekaj trdno zagotovljenega, kar bi bilo enkrat doseženo in bi obstajalo za vse večne čase, temveč se vedno znova sooča s svojimi temeljnimi problemi. Vedno znova je izpostavljena javni pozornosti, kritiki in nadzoru (1997, str. 171).

Korez potrjuje teze naštetih avtorjev in hkrati izraža zavedanje zaposlenih, ki se v oboroženih silah ukvarjajo z odnosi z javnostmi, ko omenja, da izvajalci komunikacijskih strategij upoštevajo javno mnenje pri načrtovanju svojega dela in poskušajo nanj z različnimi oblikami proaktivnega dela tudi vplivati. Posebej poudari, da javno mnenje izraža predvsem aktivna javnost, ki ima nespremenljiva in aktivna stališča. Pomemben del za področje dela odnosov z javnostmi pa je tudi neaktivna javnost, ki postane aktivna ob kakšnem širšem splošnem vprašanju. Tako oborožene sile brez podpore javnosti ne morejo učinkovito izvajati nobenih novih nalog, pri čemer posebej izpostavlja pomen javnega mnenja v povezavi s sodelovanjem oboroženih sil v mednarodnih operacijah in na misijah (Korez, 2008, str. 61).

\section{METODOLOŠKI PRISTOP K EVALVACIJI ODNOSOV Z JAVNOSTMI V SLOVENSKI VOJSKI}

Ministrstvo za obrambo ima več organizacijskih enot, na primer SV, upravni del, Upravo RS za zaščito in reševanje (URSZR) in druge. Za področje odnosov z javnostmi je organizirana Služba za strateško komuniciranje. SV in URSZR imata svoja predstavnika za odnose z javnostmi, pri čemer ima SV v ta namen tudi poseben sektor.

Da bi ugotovili, kako kakovostno je področje dela odnosov z javnostmi v SV, je bilo v Sektorju za odnose z javnostmi na Generalštabu SV izvedenih več različnih projektov, pri katerih smo se osredotočili na notranjo in zunanjo javnost.

Notranjo javnost razumemo kot vse zaposlene v obrambnem sistemu, ki prek različnih medijev spremljajo dogajanje v njem in zunaj njega. Ministrstvo ima na voljo poseben notranji spletni portal, imenovan Infotočka, prek katerega vsak dan obvešča zaposlene o najrazličnejših aktualnih vsebinah in dogodkih, ki v njem nastajajo. Vsebuje pa tudi različne stalne rubrike o pravnih aktih, sindikatih, športu, izobraževanju in usposabljanju ter drugih področjih. Za komuniciranje z zaposlenimi ima SV tudi več publikacij, ki so namenjene seznanjanju bralcev z različnimi dejavnostmi posameznih enot (revija Prvi, Prava smer, Modri), z vojaškim učnim procesom (Vojaškošolski zbornik) ali posameznim področjem (Vojaška zgodovina). 
Zunanjo javnost razumemo kot vse tiste posameznike, združenja ali skupine, ki niso zaposleni $\mathrm{v}$ obrambnem sistemu. SV z zunanjo javnostjo komunicira prek različnih objav na spletnih staneh ministrstva in SV, z izjavami tiskovnega predstavnika in drugih zaposlenih, $\mathrm{z}$ različnimi publikacijami ter organiziranjem tiskovnih konferenc in drugih dogodkov za medije in posamezne ciljne skupine.

Gre za ciljno skupino, ki je veliko težje določljiva in dosegljiva za vrednotenje v smislu evalvacije. Kdo so torej tisti deli zunanje javnosti, ki lahko najbolje ocenijo delo na področju odnosov z javnostmi? Po naših ugotovitvah so to predstavniki medijev, ki s SV bolj ali manj redno sodelujejo. Da bi dobili širše vedenje, smo se odločili več pozornosti nameniti tudi rezultatom CJM, in sicer pri merjenju zaupanja slovenske javnosti v institucije, s poudarkom na SV, in interpretaciji teh rezultatov.

\begin{tabular}{|c|c|c|c|}
\hline \multirow{4}{*}{$\begin{array}{r}\text { Preglednica 1: } \\
\text { Pristopi k } \\
\text { evalvaciji po } \\
\text { Rühlu v povezavi } \\
\text { s posameznimi } \\
\text { projekti SV } \\
\text { na področju } \\
\text { odnosov z } \\
\text { javnostmi }\end{array}$} & $\begin{array}{l}\text { Pristopi k evalvaciji } \\
\text { po Rühlu }\end{array}$ & Notranja javnost & Zunanja javnost \\
\hline & laični pristop & $\begin{array}{c}\text { prvi projekt: Notranji spletni portal } \\
\text { INFOTOČKA }\end{array}$ & $\begin{array}{c}\text { četrti projekt: Zaupanje javnosti } \\
\text { v SV }\end{array}$ \\
\hline & strokovni & $\begin{aligned} & \text { drugi projekt: } \text { Komuniciranje z } \\
& \text { notranjo javnostjo SV }\end{aligned}$ & $\begin{aligned} \text { tretji projekt: } & \text { Komuniciranje SV s } \\
& \text { predstavniki medijev } \\
\text { četrti projekt: } & \text { Zaupanje javnosti } \\
& \text { V SV }\end{aligned}$ \\
\hline & akademski & & $\begin{array}{c}\text { četrti projekt: Zaupanje javnosti } \\
\text { v SV }\end{array}$ \\
\hline
\end{tabular}

\subsection{Prvi projekt: Notranji spletni portal INFOTOČKA}

Notranja spletna stran ministrstva je bila leta 2009 prenovljena. Dodatno je bila uvedena Infotočka, komunikacijsko orodje oziroma portal za notranje informiranje pripadnikov SV.

Za evalvacijo Infotočke je bil po njeni uvedbi zaposlenim razdeljen poseben vprašalnik, zasnovan tako, da bi ugotovili njeno uporabnost, aktualnost in funkcionalnost, uredili celostno podobo in dodali nove informacije, rubrike ali komunikacijska orodja, ki bi čim bolj izpolnjevala pričakovanja zaposlenih v SV.

Vprašalnik je bil razdeljen 530 pripadnikom SV, in sicer vojakom, podčastnikom in nižjim vojaškim uslužbencem ${ }^{6}$ (kar je 10-odstotni delež v vzorcu vseh). Vprašalnike so izpolnjevali v času od 15. marca do 15. aprila 2010.

${ }^{6}$ Leta 2010 je bilo njihovo število približno 5300. 


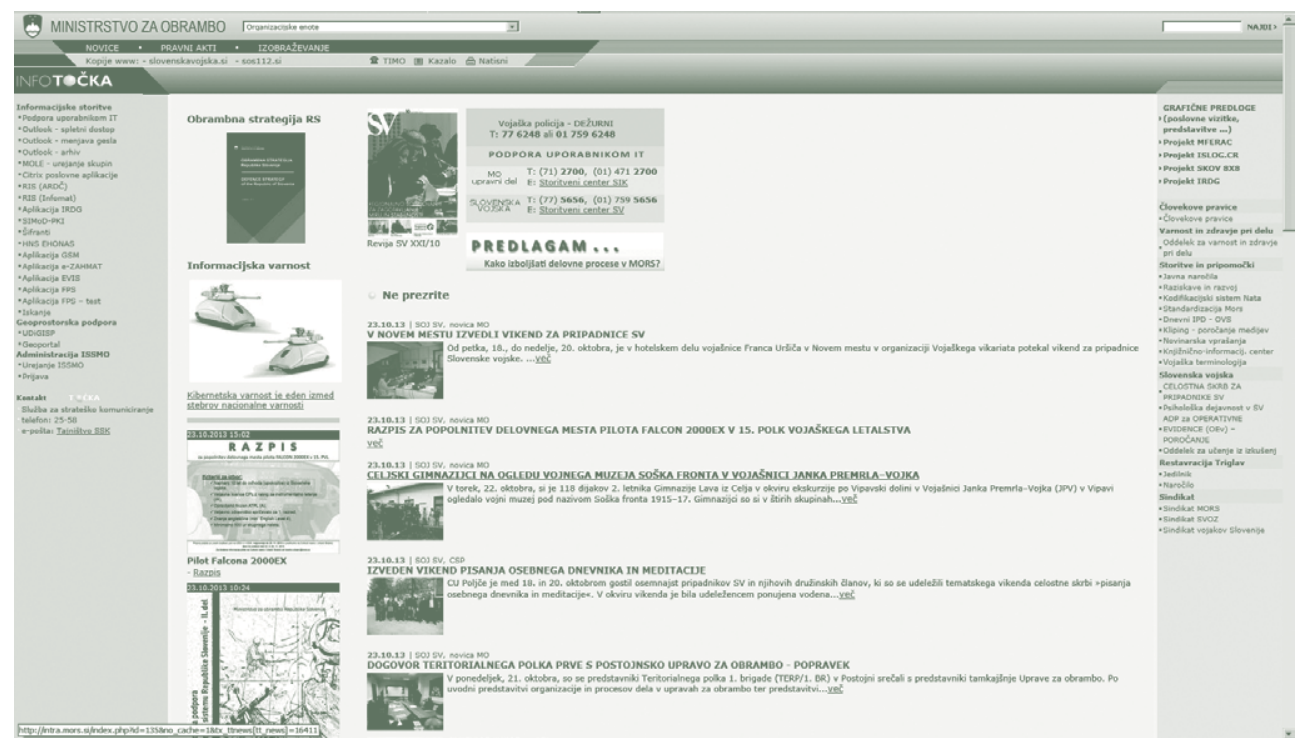

\subsection{Drugi projekt: Komuniciranje z notranjo javnostjo SV}

Evalvacija notranjega komuniciranja v SV je bila opravljena v sodelovanju z agencijo Pristop. Namen vprašalnika je bil:

- pridobiti informacije o medijskih navadah zaposlenih častnikov v SV;

- pridobiti oceno trenutnega stanja notranjega komuniciranja v SV;

- opredeliti potrebe, želje in pričakovanja zaposlenih častnikov, povezana z notranjim komuniciranjem v SV;

- odkriti največje vrzeli v notranjem komuniciranju v SV, ki bodo podlaga za njegovo nadaljnje upravljanje.

Vprašalnik je vseboval tri vsebinske sklope: oceno notranjega komuniciranja v SV (kako pogosto iščejo informacije o SV in kje jih dobijo, kako jih ocenjujejo, kaj predlagajo za izboljšanje), medijsko potrošnjo (katere zunanje in notranje medije spremljajo, kako pogosto, kje dobijo največ informacij) ter demografske podatke o sodelujočih.

Vprašalnik je bil objavljen na spletnih straneh http://surveymonkey.com/s/mors-vprasalnik. Častniki so ga izpolnjevali v času od 25. oktobra do 10. novembra 2010. Dobili smo 210 izpolnjenih vprašalnikov (kar je približno 17-odstotni delež vseh častnikov, zaposlenih $\mathrm{SV}^{7}$ ). 


\subsection{Tretji projekt: Komuniciranje SV s predstavniki medijev}

Vprašalnik za predstavnike medijev je bil pripravljen z namenom, da se ovrednoti in izboljša področje dela odnosov z javnostmi. Sestavljen je bil iz treh sklopov, in sicer mediji in SV, sodelovanje predstavnikov medijev s predstavniki za odnose $\mathrm{z}$ javnostmi v SV ter obiski predstavnikov medijev, ki jih v mednarodnih operacijah in na misijah organizira SV. Vprašalniki so bili poslani predstavnikom medijev in njihovim uredništvom konec decembra 2011 in v začetku januarja 2012. V evalvaciji so bili upoštevani vsi vprašalniki, ki so bili izpolnjeni do konca februarja 2012.

\section{4 Četrti projekt: Zaupanje javnosti v SV}

V sodelovanju z revijo Obramba je bil izveden projekt, katerega cilj je bil povabiti k sodelovanju različne strokovnjake na področju odnosov z javnostmi in pridobiti njihova mnenja o zaupanju slovenske javnosti v SV v povezavi z rezultati CJM, ki večkrat na leto meri zaupanje javnosti v javne institucije.

Na povabilo so se odzvali: nekdanji zaposleni v agenciji Pristop, ki je sodeloval v medijskih akcijah skupaj s $\mathrm{SV}^{8}$, dve doktorici znanosti s Katedre za obramboslovje Fakultete za družbene vede in trije novinarji, ki redno in profesionalno spremljajo aktivnosti SV. Mnenja vseh so bila objavljena v reviji Obramba julija 2013, skupaj z intervjujem s tiskovnim predstavnikom SV.

V konceptu pristopa k evalvaciji je bil upoštevan tako imenovani celostni pristop, $\mathrm{s}$ katerim smo želeli zajeti vse tiste javnosti, ki kakor koli lahko prispevajo k vrednotenju odnosov z javnostmi v SV. V prvem primeru so bili ciljna javnost vojaki, podčastniki in nižji vojaški uslužbenci, v drugem so se na vprašalnik odzvali častniki in višji vojaški uslužbenci, v tretjem so sodelovali predstavniki večjih medijskih hiš in lokalni novinarji, v četrtem pa splošna laična javnost, zajeta v vzorec vprašanih v anketi $\mathrm{CJM}^{9}$, in tisti, ki se z odnosi zjavnostmi ukvarjajo profesionalno ali akademsko. Tako smo si prizadevali čim bolj upoštevati različna teoretična izhodišča domačih (Verčič, Serajnik Sraka itn.) in tujih avtorjev (Bernays, Huntington itn.), da bi evalvacija tako prispevala $\mathrm{h}$ kakovostnemu vrednotenju in stvarni oceni stanja, hkrati pa podala usmeritve za prihodnje delo. V metodološkem smislu pa smo izhajali iz pristopov k evalvaciji po Rühlu (2008).

\footnotetext{
Leta 2010 je SV skupaj s Pristopom prejela eno izmed nagrad Effie za tržno učinkovitost. Ponosni nase je bila predstavitev, ki je imela temeljni cilj seznaniti mlade z možnostjo poklicnega vključevanja $v$ SV. Zasnovana je bila $v$ času velike gospodarske rasti, ko je trg delovne sile intenzivno zaposloval kader, zaposljiv tudi v SV. $S V$ je skupaj z Ministrstvom za obrambo izbrala agencijo in pripravila celovit projekt, ki je bil usmerjen $v$ nagovarjanje mladih za zaposlitev v SV. Zaradi te celovitosti je bila to posebna promocijska akcija, ki je imela tržno učinkovitost (intervju s Korezom v reviji Obramba, julij 2013).

9 Vzorci v povprečju vsebujejo med 800 in 1000 sodelujočih pri vsaki meritvi posebej. Več na http://www.cjm. si/?q=PB_rezultati, 18. 10. 2013.
} 


\section{RAZISKAVA}

\subsection{Infotočka - rezultati}

Prejeli smo 605 izpolnjenih vprašalnikov. Od tega so jih 70 odstotkov izpolnili vojaki, 16 odstotkov podčastniki, 9,5 odstotka častniki in štiri odstotke vojaški uslužbenci. $Z$ vidika celostne podobe je bila Infotočka ocenjena s povprečno oceno 2,93, organiziranost rubrik s povprečno oceno 2,79 , preglednost z 2,81, funkcionalnost vsebin s povprečno oceno 2,78 , aktualnost z 2,8 , način posredovanja informacij z 2,83 in uporabnost z 2,69.

V rubriki »vaše mnenje«, v kateri je bil predviden prostor za predloge vprašanih, se je pojavilo veliko različnih predlogov, ki pa so bili zelo specifični in povezani s posameznimi področji ali enotami.

$\mathrm{Na}$ vprašanje, o katerih področjih bi si zaposleni želeli pridobiti več informacij, smo dobili odgovore, ki so razvrščeni glede na izkazani interes vprašanih (možnih več odgovorov). Največ zanimanja je bilo za informacije, povezane z možnostmi napredovanja (363), na drugem mestu so bile informacije o plačah (334), na tretjem pravne razlage zakonodaje (314), na četrtem možnosti dela v mednarodnih operacijah in na misijah (299) ter o vojaškem izobraževanju in usposabljanju (299), na šestem mestu o jezikovnih tečajih po sistemu e-izobraževanja (274), na sedmem o vojaškem izobraževanju in usposabljanju v tujini (266) ter o dopustih (266), na osmem o možnostih dela v tujini (258) in na zadnjem, devetem mestu, o izobraževanju na splošno (44).

V rubriki »vaše mnenje in predlogi« so vprašani našteli: več informacij o športnih dogodkih, ki jih organizira SV ali v njih sodeluje, o spremembah organiziranosti delovanja SV in MO, o možnostih različnih letovanj, streliščih, uradnih stališčih SV do komentarjev, povezanih s SV v medijih, o usposabljanjih na področju informacijske tehnologije, o razpisih za prosta delovna mesta v SV in na MO, na misijah in $\mathrm{v}$ tujini ter drugo.

\subsection{Kakovost notranjega komuniciranja v SV z vidika zaposlenih}

Rezultati anketiranja, ki je bilo organizirano v sodelovanju z agencijo Pristop, so bili na rednem mesečnem usposabljanju aprila 2011 na Vrhniki predstavljeni zaposlenim, ki delajo na področju odnosov z javnostmi v SV. Sestavljeni so bili iz dveh sklopov: kakovosti notranjega komuniciranja v SV in analize glasil.

Največ informacij dobijo zaposleni od neposredno nadrejenih. Na Likartovi lestvici od 1 do 5 so vprašani izbrali zanje povprečno oceno 3,36. Sledijo informacije z Infotočke s 3,35, na tretjem mestu so sodelavci z oceno 3,33 in na četrtem elektronska pošta $z$ oceno 3,27 . Na petem mestu je bila revija SV z oceno 2,67, na šestem drugi nadrejeni z oceno 2,59 in na sedmem revija Obramba z oceno 2,55. 
Publikacije SV so si kot vir informacij sledile po tem vrstnem redu: Bilten Slovenske vojske z oceno 1,79, Prvi z oceno 1,44, Prava smer z 1,24, Častno in predano z oceno 1,20 in Ujma z 1,19.

Kot vir informacij so se neposredno nadrejeni v deležu odgovorov z možno izbiro pogosto in zelo pogosto pojavili v 52,2 odstotka, drugi sodelavci v 48 odstotkih, Infotočka v 53,2 odstotka in elektronska sporočila v 53,9 odstotka.

Med informacijami, o katerih bi zaposleni želeli vedeti več, se je na prvem mestu znašla tema o delovanju drugih vojsk, in sicer je 75 odstotkov vprašanih menilo, da je o tej temi premalo informacij. O napredovanju v obrambnem sistemu bi želelo vedeti več 73,8 odstotka vprašanih, o drugih organizacijskih enotah pa 71 odstotkov, o zaposlovanju novih vojakov 69,3 odstotka, o strategiji, viziji in ciljih obrambnega sistema 67,2 odstotka vprašanih, o družbeno odgovornem delovanju sistema 66,5 odstotka, o delovanju Nata 66,6 odstotka itn.

Zaposleni si v rubriki o temah, o katerih bi želeli biti obveščeni po svoji izbiri, najbolj želijo korektne obveščenosti o delovanju znotraj sistema, in sicer je takih 34,5 odstotka, na drugem mestu so kadrovske zadeve z 22,7 odstotka, ki jim sledijo teme o razvoju SV z 21,8 odstotka.

Publikacije so vprašani ocenili kot pretežno informativne, bogate s slikovnim gradivom. Kot prednosti so prepoznali redno izhajanje, pestro izbiro avtorjev in intervjuje. Hkrati pa so po mnenju vprašanih glasila precej statična. Narava obveščanja je zelo formalna, nedinamična oziroma toga. Prevladujejo vsebine o organizaciji, premalo je vsebin o ljudeh, stroki, rubrike so premalo pestre. Kot govorci se pojavljajo predvsem zaposleni z višjimi čini in na višjih položajih. Jezik je »pust«, naslovi »nedinamični in zgolj informativni«. Kot dober primer glasila je bila izpostavljena revija Prvi.

Ključne ugotovitve iz vprašalnika so:

- orodja notranjega komuniciranja so omejeno učinkovita. Na voljo jih je dovolj, vendar niso v celoti izkoriščena;

- v sistemu sta dve skupini zaposlenih. Prva je skupina vojakov s časovno omejeno pogodbo o zaposlitvi. Zanimajo jih informacije o delovnem razmerju, so mlajši od 36 let, imajo manj kot 11 let delovne dobe in so najmanj zadovoljni z notranjim komuniciranjem. Zanimajo jih komunikacijska orodja mlajših generacij in večino informacij iščejo zunaj sistema. Drugo skupino predstavljajo zaposleni za nedoločen čas, v povprečju imajo višjo izobrazbo, višje čine in več delovne dobe. Njihova pričakovanja, povezana $\mathrm{z}$ internim komuniciranjem, so veliko večja, bolje poznajo organizacijo in poslanstvo sistema, uporabljajo vsa komunikacijska orodja in so z njimi veliko bolj zadovoljni kot prva skupina;

- medosebno komuniciranje je na razmeroma visoki ravni. Zelo dobra je tudi komunikacija z zunanjimi akterji, kot so na primer družinski člani, prijatelji in znanci, ki sooblikujejo tako notranje kot zunanje komuniciranje med zaposlenimi; 
- glede na skupino orodij je na prvem mestu najbolj uporabljena osebna komunikacija, sledijo ji elektronska in pisna komunikacija, spletne strani ter na petem mestu notranja glasila;

- med ključne pomanjkljivosti uvrščajo notranjo komunikacijo, ki je usmerjena predvsem v delovna navodila, drugih vsebin ni. Informacije niso pravočasne in kakovostne, prej netočne in zavajajoče;

- kot ključne izboljšave predlagajo zaposleni več komuniciranja na neformalni ravni (srečanja z vodstvom zunaj delovnega okolja, prostočasne aktivnosti ipd.), izboljšanje sistema povratnih informacij in nadgradnjo informacijskih orodij;

- na vsebinski ravni si zaposleni želijo več kadrovskih informacij, strateških vsebin, povezanih z obrambnim sistemom, več vsebin zunaj dogajanja SV ter korektno in sprotno obveščanje.

\subsection{Kako komuniciranje $\mathrm{z}$ javnostmi SV ocenjujejo predstavniki medijev}

Ugotavljali smo, kako pogosto mediji spremljajo dogajanje v SV. Dobili smo podatek, da 23 odstotkov vseh, ki so vprašalnik izpolnili, to počne vsak dan, 27 odstotkov enkrat na teden, 15 odstotkov enkrat na mesec in 35 odstotkov občasno.

Na vprašanje, kje dobijo največ informacij o SV, so na prvo mesto uvrstili različne vire na spletu, na drugo uradne predstavnike za odnose z javnostmi v SV, na tretje radio, televizijo in časopise ter na četrto mesto uradne spletne strani SV in ministrstva. Na vprašanja, ali je slovenska javnost prek medijev dovolj obveščena o poslanstvu in nalogah SV, o aktualnih dogodkih in nalogah v tujini, je 54 odstotkov vprašanih odgovorilo pozitivno in 46 odstotkov negativno.

Kakovost informacij o SV, ki se pojavljajo v slovenski javnosti, je bila po posameznih merilih ocenjena, kot je prikazano v grafu 1.
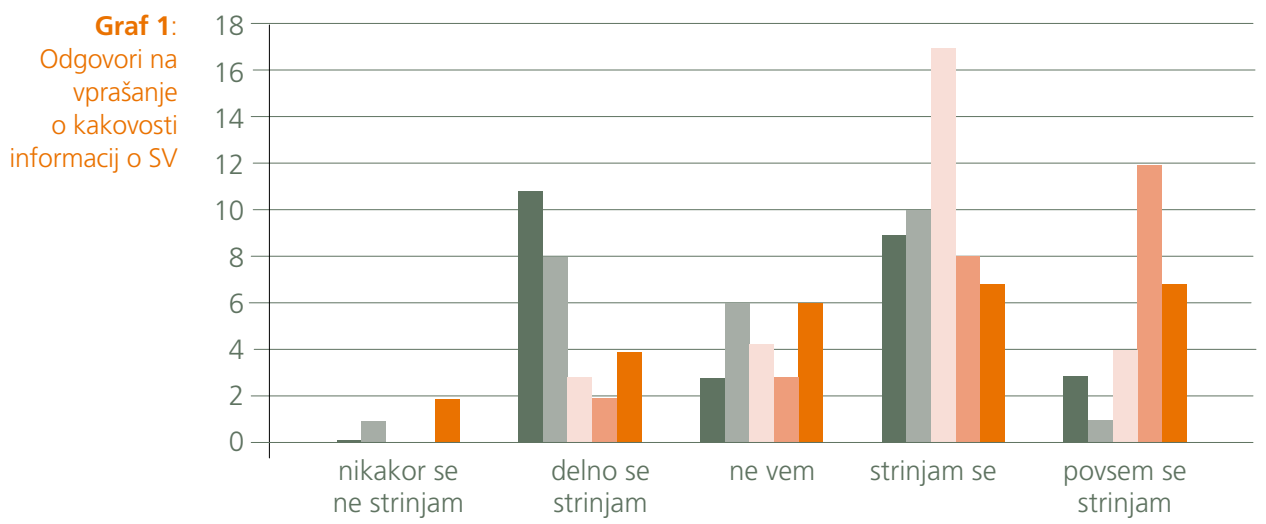

Info. je dovolj

so točne

so aktualne

pomembne za slov. javnost

pomembne za splošno varnost v regiji 
Pri vsebinah, povezanih s SV, ki najbolj zanimajo slovensko javnost, so se predstavniki medijev največkrat odločili za poslanstvo in naloge SV v mednarodnih operacijah in na misijah. Na drugem mestu so izbrali pomoč prebivalstvu v okviru nalog zaščite in reševanja, na tretjem izredne dogodke ter na četrtem civilno-vojaško sodelovanje. Sledijo življenje in delo v vojašnicah na petem mestu, na šestem vojaško urjenje in izobraževanje ter na zadnjem, sedmem mestu, vojaške vaje.

Na vprašanje, o katerih vsebinah bi bilo dobro več poročati, so vprašani označili in razvrstili vse prej naštete vsebine po enakem vrstnem redu glede na pomembnost. Med predloge pa so zapisali, da bi SV morala:

- v sodelovanju z RTV Slovenija po vzoru drugih držav poskrbeti za predvajanje dokumentarnih oddaj o delu in življenju v vojašnicah;

- nameniti več pozornosti doseganju svoje pozitivne podobe v javnosti;

- slovensko javnost bolje obveščati o porabi proračunskega denarja, ker jo to zelo zanima.

Ocena dela zaposlenih na področju odnosov z javnostmi po posameznih merilih je prikazana $v$ grafu 2 .

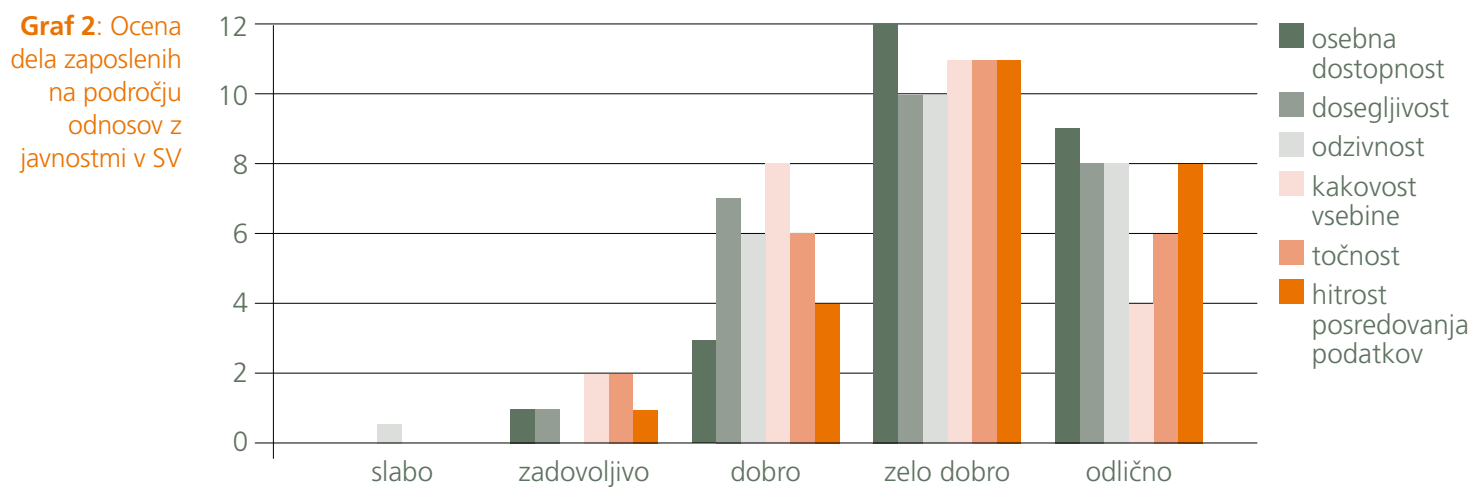

Predstavniki medijev so kot prvi vir za pridobivanje informacij o SV izbrali različne spletne strani. Ocena spletnih strani ministrstva je prikazana v grafu 3. 


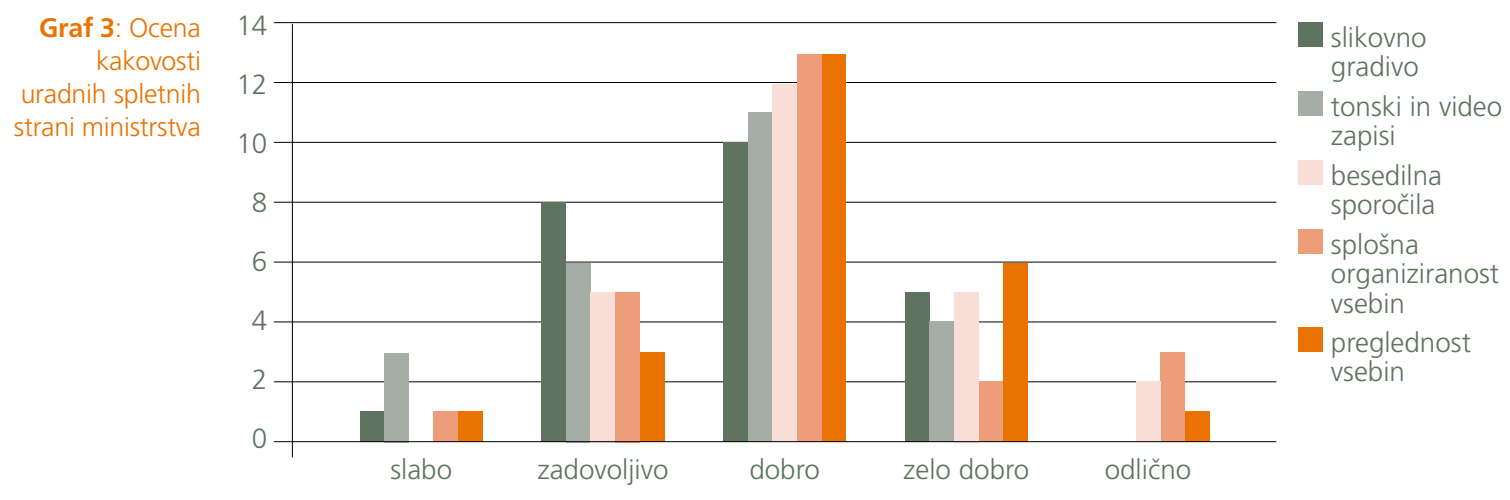

Med predlaganimi vsebinami za obogatitev spletnih strani so vprašani v rubriki odprtega tipa predlagali več poudarka predstavitvi posameznikov, na primer poveljnikov, odlikovancev in enot ter slikovnemu gradivu iz mednarodnih operacij in $\mathrm{z}$ misij.

Predstavniki za odnose z javnostmi za predstavnike slovenskih medijev priložnostno organiziramo obiske pripadnic in pripadnikov SV v mednarodnih operacijah in na misijah. Zanimalo nas je, kako pogosto se predstavniki medijev v vzorcu udeležujejo takih potovanj.

Enkrat se je takega obiska udeležilo 31 odstotkov vprašanih, dvakrat 38 odstotkov, večkrat 23 odstotkov, nikoli pa 42 odstotkov.

Da je taka potovanja treba organizirati večkrat, je menilo 85 odstotkov vprašanih.

\subsection{Strokovni in akademski pogled na kakovost odnosov z javnostmi v SV}

Projekt Zaupanje javnosti v SV je bil izveden v sodelovanju z revijo Obramba. Junija 2013 je CJM objavil povsem sveže rezultate meritev javnega mnenja, po katerih je SV ponovno na prvem mestu po zaupanju v javne institucije tako kot že januarja 2013 in v merjenjih prejšnja leta.

Kot je komentirala Garbova (2013, str. 8), se predstavniki SV ${ }^{10}$ radi v javnosti pohvalijo kot zaupanja vredna institucija, hkrati pa je spomnila, da so oborožene sile v demokratičnih državah praviloma na vrhu lestvic zaupanja javnosti, pri čemer je to zaupanje bistveno višje ${ }^{11}$ kot v Sloveniji, kjer je delež zaupanja približno 50odstoten. Na lestvici 31 držav imata manjši delež kot Slovenija samo še dve državi.

\footnotetext{
${ }^{10}$ Garbova se je oprla na intervjuje načelnikov GŠSV, generalmajorja Alojza Šteinerja in brigadirja Dobrana Božiča.

"Leta 2010 je bilo zaupanje v oborožene sile evropskih držav naslednje: Nemčija $70 \%$, Grčija 67 \%,

Francija $71 \%$, Italija $65 \%$, Avstrija $72 \%$, Estonija $80 \%$, Slovaška $72 \%$ in Madžarska $57 \%$.
} 


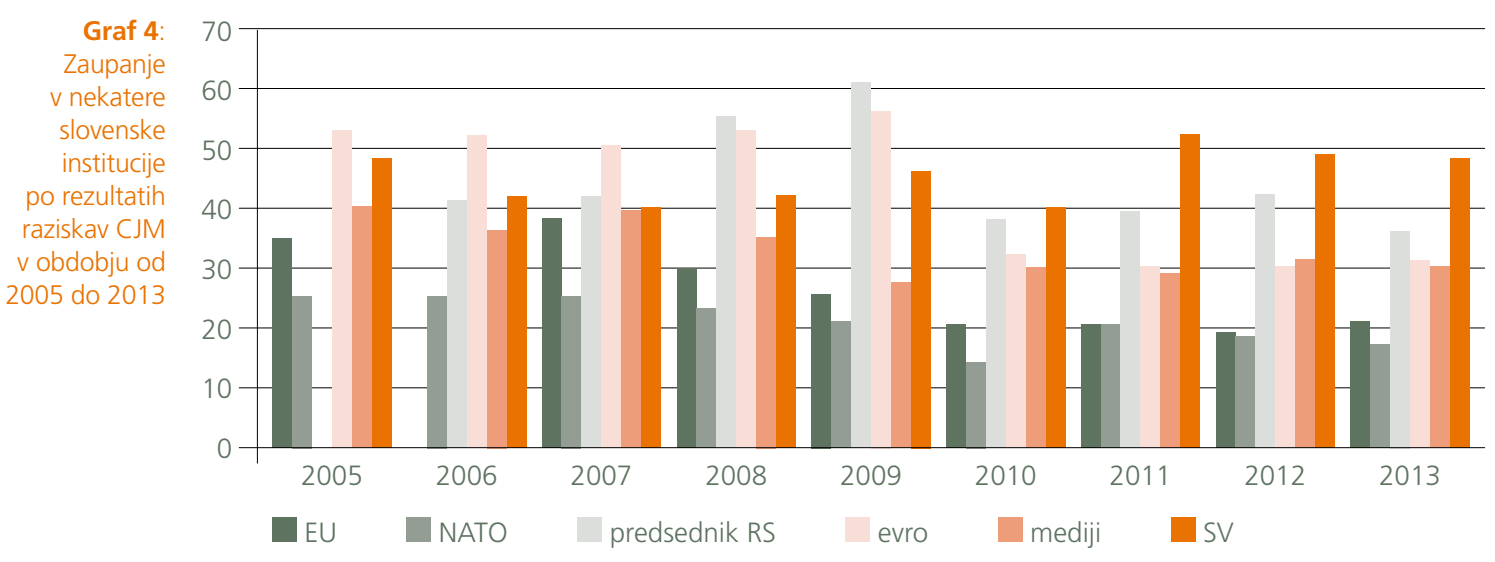

Vir: http://www.cjm.si/node, 18. 9. 2012.

V nacionalnem smislu pa Vuga izpostavi dejstvo, da javnost sicer podpira SV in njeno delovanje v MOM, a le, dokler vse poteka po načrtu, dokler ni izgredov, ranjenih in mrtvih (Vuga, 2013). Brankovič je izpostavil dejstvo, da ima SV veliko strokovnjakov s posebnimi vrstami znanja, ki bi jih lahko pogosteje delila s slovensko javnostjo, hkrati pa ima veliko priložnosti, ki jih ne izkoristi dovolj. Pri tej presoji se opira na ameriške izkušnje promoviranja vojske (Brankovič, 2013, st. 10). Kocjan pravi, da je vojska v javnem političnem diskurzu najpogosteje »nebodigatreba«, kateremu se v javnofinančni krizi naprej odvzamejo sredstva, ker je pač vse treba najprej preizkusiti na vojski, včasih pa bi vojsko kar ukinili. Zaradi tega je razmeroma visoka in stalna podpora vojski pravzaprav paradoks. Kocjan nadaljuje, da slovenska javnost zelo dobro loči med tem, kaj vojska v svojem bistvu je, in kakšni so politični vplivi nanjo (Kocjan, 2013, str. 11). Moč SV je v njenem tihem delu doma, za aktivnosti v MOM vedo le redki, nikakor pa ne tisti, ki jih zanima samo to, kaj se dogaja do konca domače ulice (Tepina, 2013, str. 12). Izkušenj na področju odnosov z javnostmi je bil posebej vesel Krajner, ki je kot predstavnik agencije Pristop s SV sodeloval pri medijski kampanji Ponosni nase. Pravi, da se tisti, ki so zaposleni v gospodarstvu, lahko učijo komuniciranja od SV, saj ta ne sledi slepo komunikacijskim trendom, temveč jih oblikuje (Krajner, 2013, str. 7).

\section{RAZPRAVA}

Na podlagi opisanih projektov lahko v SV notranjo javnost razdelimo na dve ciljni skupini. V prvo uvrščamo zaposlene z manj delovne dobe, torej mlajše generacije s pogodbo o zaposlitvi za določen čas, ki jih najbolj zanimajo njihov status v sistemu, plača in možnosti, kako to plačo zaslužiti, kako napredovati, se dodatno izobraziti in usposobiti za nove naloge in priložnosti ter še posebej, kako podaljšati pogodbo. 
Ta skupina gradi svojo profesionalno vojaško kariero in zanima jo vse, kar je s tem povezano. V drugo skupino spadajo zaposleni z daljšo delovno dobo, s pogodbami o zaposlitvi za nedoločen čas in z logiko delovanja javnih uslužbencev. Večina ima višjo stopnjo izobrazbe, spremlja aktualno dogajanje doma in po svetu ter želi vedeti več o aktualnih tokovih in prihodnjih spremembah na varnostno-obrambnem področju. Ti se počutijo bolj povezani z obrambnim sistemom, mu bolj pripadajo, zanima jih, kaj se dogaja drugim zaposlenim na osebni ravni in želijo biti aktivni ustvarjalci prihodnosti $\mathrm{v}$ sistemu

Neodvisno od tega pa si vsi želijo aktualnih in korektnih informacij. Posebej zanimivo $\mathrm{v}$ dobljenih rezultatih je, da si zaposleni želijo vedeti več o posameznikih znotraj sistema, kot pa o vodilnih. Zanimajo jih izkušnje drugih pri opravljanju nalog v tujini, v MOM, na vojaških izobraževanjih in usposabljanjih.

Elektronska komunikacija in uporaba spletnih strani sta poleg osebnega komuniciranja zelo uporabljeni orodji, zato je treba v prihodnosti takemu načinu komuniciranja nameniti več pozornosti v vsebinskem in tehničnem smislu.

Vse to se je potrdilo tudi na primeru vrednotenja komuniciranja z zunanjimi javnostmi oziroma s predstavniki medijev. Tudi ti uporabljajo predvsem osebno komunikacijo, a je zanje enako pomembna tudi pravočasna in korektna informiranost na spletu. Kot so pokazali rezultati, imajo spletne strani ministrstva, tako za notranjo javnost (Infotočka) s povprečno oceno 2,8 in zunanjo javnost s povprečno oceno 3, v razponu od 1 do 5 še veliko odprtih možnosti in priložnosti, kako javnostim ponuditi več in bolje.

Na primeru predstavnikov medijev, novinarjev in akademikov smo ugotovili, da tudi slovensko (zunanjo) javnost lahko razdelimo na dve cilji skupini. Tako v prvo zagotovo spadajo večje nacionalne medijske hiše ter akademski krogi. Zanimajo jih informacije o SV na splošno, še posebej pa vsebine strateškega pomena, kot so na primer financiranje obrambnega sistema in poraba sredstev v njem, načrtovanje aktivnosti na obrambnem področju in mednarodno sodelovanje, postopki sprejemanja dolgoročnih odločitev, predvideni vložki v sistem ter prihodnje koristi za posameznika in predvsem državo. Sogovorniki v tej skupini so strokovnjaki, zahtevni v svojih pričakovanjih, redno spremljajo dogajanja, so analitični in kritični v svojih interpretacijah. Predstavniki za odnose z javnostmi v SV se jim morajo posvetiti v celoti, torej biti odzivni, korektni in profesionalni.

V drugo skupino uvrščamo lokalne medije. Ti navadno niso pozorni na strateške odločitve, temveč jih zanimata lokalno okolje in življenje v njem. Tako je SV zanimiva zanje v okoljih, kjer so objekti SV, še posebej vojašnice in zaposleni v njih. Tam najbolj pride do izraza tako imenovano civilno-vojaško sodelovanje in pa seveda to, da so zaposleni v SV tudi sestavni del lokalnega prebivalstva in nenehno prisotni v tem okolju. Zanimajo jih izkušnje posameznikov in posebnosti njihovega poklica, vpetost takega posameznika v družbo in podobne sociološke vsebine. 
Komentar Garbove o primerjavi zaupanja splošne javnosti v SV glede na zaupanje v oborožene sile drugih držav ne spremeni dejstva, da se SV pojavlja na prvih mestih po zaupanju glede na druge državne institucije v Sloveniji. Za te nismo preverjali primerjalnih podatkov v drugih državah. Za našo sklepno oceno je pomembno vedeti tudi, kakšen je delež tistih, ki SV ne zaupajo. Tudi po tem merilu je SV na prvem mestu - po najmanjšem deležu.

Sklep Delež zaposlenih z daljšim delovnim stažem izraža podobna stališča in pričakovanja na področju odnosov z javnostmi kot splošna slovenska javnost. So previdni, želijo biti obveščeni in sooblikovati svojo prihodnost kot sestavni del slovenske javnosti in obrambnega sistema. Zanimajo jih strateške odločitve, dogajanje v oboroženih silah v mednarodnem okolju in vpetost SV v splošno družbeno okolje. So kritični, tako kot predstavniki večjih medijskih hiš, ki so specializirani za področje obrambe ali nacionalnovarnostnega sistema.

Po drugi strani imamo mlajše generacije zaposlenih, ki vojaštvo razumejo strogo profesionalno, vedo, zakaj so prišli v sistem, kaj hočejo in kako bodo to dosegli. Vse to kažejo tako v SV kot tudi v domačem okolju. Tako sta ugotovila Tepina in Kocjan, pa tudi sami so se tako opredelili v vprašalnikih, ki so jih izpolnili.

V preglednici 2 so strnjene ključne ugotovitve evalvacije v odnosu do posameznih javnosti in po posameznih projektih, ki so hkrati tudi ciljne skupine za komuniciranje. Nekatere ugotovitve smo sproti upoštevali tudi pri našem delu. Letos smo okrepili pojavljanje SV na socialnih omrežjih in tako dosegli mlajše generacije v delu notranje in zunanje javnosti. Tako smo se posredno izognili administrativnim, varnostnim in informacijskih oviram, ki so preprečevale bolj dinamično komuniciranje prek uradnih spletnih strani SV in MO.

Med zahtevnejše naloge za komuniciranje v prihodnje zagotovo spadajo aktualne in strateške vsebine, za katere je zanimanje večje od ponudbe.

Znanja in izkušenj je v SV dovolj. V prihodnje bomo morali najti dodatne načine za spodbujanje nastajanja pisnih, slikovnih in avdio vsebin. Navedeno je povezano $\mathrm{s}$ kadrovskimi in finančnimi viri, potrebnimi za različne oblike usposabljanja, nakup tehnične in informacijske opreme ter organizacijo različnih dogodkov, zanimivih za javnost. 


\begin{tabular}{|c|c|c|c|}
\hline \multirow{4}{*}{$\begin{array}{r}\text { Preglednica } \\
2: \text { Pristopi } \\
\text { k evalvaciji } \\
\text { po Rühlu, v } \\
\text { povezavi s } \\
\text { posameznimi } \\
\text { projekti na } \\
\text { področju } \\
\text { odnosov z } \\
\text { javnostmi, ki } \\
\text { smo jih izvedli } \\
\text { v SV, in s } \\
\text { predlaganimi } \\
\text { izboljšavami }\end{array}$} & $\begin{array}{l}\text { Pristopi k evalvaciji } \\
\text { po Rühlu }\end{array}$ & Notranja javnost & Zunanja javnost \\
\hline & laični pristop & $\begin{array}{l}\text { Notranji spletni portal Infotočka: } \\
\text { - izboljšati celostno podobo } \\
\text { portala, aktualizirati novice, } \\
\text { - izboljšati kakovost s predlaganimi } \\
\text { vsebinami. }\end{array}$ & $\begin{array}{l}\text { Zaupanje javnosti v SV: } \\
\text { - izboljšati spletne strani MO, } \\
\text { - izboljšati količino in kakovost avdio in } \\
\quad \text { video zapisov. }\end{array}$ \\
\hline & strokovni & $\begin{array}{l}\text { Komuniciranje z notranjo javnostjo SV: } \\
\text { - izboljšati osebno komunikacijo, } \\
\text { - izboljšati kakovost komunikacije s } \\
\text { predlaganimi vsebinami, } \\
\text { - komentirati aktualne teme o SV, ki se } \\
\text { pojavljajo v javnosti, } \\
\text { - ponuditi več strateških tem, } \\
\text { - izboljšati dinamiko publikacij/glasil SV. }\end{array}$ & $\begin{array}{l}\text { Komuniciranje SV s predstavniki } \\
\text { medijev: } \\
\text { - izboljšati spletne strani SV, } \\
\text { - izboljšati količino in kakovost avdio in } \\
\text { video zapisov, } \\
\text { - več pozornosti nameniti lokalnim } \\
\text { medijem. } \\
\text { Zaupanje javnosti v SV: } \\
\text { - športne in humanitarne dogodke bolj } \\
\text { povezati z javnostjo in vabiti medije } \\
\text { - na dogodke, ki jih organizirajo } \\
\text { strokovni krogi, vključiti tudi } \\
\text { strokovnjake iz SV }\end{array}$ \\
\hline & akademski & & $\begin{array}{l}\text { Zaupanje javnosti v SV: } \\
\text { - v dogodke, ki jih organizirajo } \\
\text { akademski in drugi strokovni krogi, } \\
\text { vključiti tudi strokovnjake iz SV }\end{array}$ \\
\hline
\end{tabular}

Kako kakovostno je torej področje dela odnosov z javnostmi v Slovenski vojski?

Glede na okoliščine, ki sta jih predstavili Garb in Vuga, ter ob upoštevanju zaupanja slovenske javnosti v druge državne institucije, lahko sklenemo samo, da zagotovo na zelo visoki ravni.

Nagrada za medijsko kampanjo je potrditev navedenega. Predstavniki medijev so razmeroma zadovoljni s predstavniki za odnose z javnostmi v SV. Predloge in pobude imata tako zunanja kot notranja javnost. Možnosti za izboljšanje kakovosti komuniciranja je še veliko. Pa je res tako?

Rezultati, upoštevani v tej evalvaciji, so nastali v zadnjih treh letih in pol in kažejo na stanje v preteklosti. Ugotovitve vsake evalvacije pa so imperativ za prihodnost. Zmanjševanje virov na vseh področjih delovanja države, zmanjševanje obrambnega proračuna, plač v javnem sektorju, števila zaposlenih ... in seveda, odnos slovenske javnosti do SV.

V prihodnje bomo še naprej iskali kreativne rešitve. Žal je slogan »z manj je več« preživet in pride čas, ko je treba povedati, da ni tako. 
Izzivov na področju dela odnosov z javnostmi v SV je še veliko. Nekaj novosti so predlagali zaposleni, nekaj drugi udeleženci v evalvaciji, največ pa jih bo nastalo sproti. In slovenska javnost bo ponovno tista, ki bo povedala, komu in koliko zaupa.

\section{Literatura}

1. Bennet, J., 2003. Evaluation Methods in Research. London, New York: Continuum Research Methods.

2. Brankovič, J., 2013. Smo danes res zaslužili 1,08 milijona? Revija Obramba, julij 2013, str. 10. Defensor, d. o. o.

3. Edmonds, M.,1988. Armed Services and Society, Leicester Unversity Press, Leicester.

4. Garb, M., 2013. Javno mnenje o Slovenski vojski dobro, a v mednarodno primerjalni luči slabše. Revija Obramba, julij 2013, str. 8. Defensor, d. o. o.

5. Hallahan, K., Holtzhausen, D., Van Ruler, B., Verčič, D., Sriramesh, K., 2008. Teorija in praksa, 6/2008, str. 628-662. Fakulteta za družbene vede, Ljubljana.

6. Huntington, S. P., 1957. The Soldier and the State, The Theory and Politics of CivilMilitary Relations. New York: Vintage Books.

7. Jelušič, L., 1997. Legitimnost sodobnega vojaštva. Fakulteta za družbene vede. Ljubljana.

8. Jelušič, L.,2003. Slovenian Public Opinion on security, defence and military issues. $V$ Marie Vlachova (ur.). The poblic image of defence and the military in Central and Eastern Europe, 182-200. Geneva: Centre for the Democratic Control of the Armed Forces (DCAF): Belgrade: Centre for Civi-l Military Relations (CCMR)

9. Kocjan, A., 2013. Ambasadorji si ne morejo privoščiti kiksov. Revija Obramba, julij 2013, str. 11. Defensor, d. o. o.

10. Korez, S., 2008. Slovenska vojska kot skupnost in njeno komuniciranje z javnostjo. Specialistično delo. Fakulteta za socialno delo, Ljubljana.

11. Krajner, A., 2013. Tisti, ki smo zaposleni v gospodarstvu, se lahko učimo od komuniciranja Slovenske vojske. Revija Obramba, julij 2013, str. 7. Defensor, d. o. o.

12. Prezelj, I., 1997. Komuniciranje med oboroženimi silami in javnostmi. Teorija in praksa XXXIV (6): str. 1020-1034.

13. Rühl, M., 2008. Public Relations Methodology Should we bother (If it exists)?. Vvan Ruler, Betteke; Tkalac Verčič, Ana; Verčič, Dejan, Public relations metrics Research and evaluation. Routlege, 2008.

14. Rus, V., Toš, N., 2005. Vrednote Slovencev in Evropejcev, Analiza vrednotnih orientacij Slovencev ob koncu stoletja. Fakulteta za družbene vede. IDV, CJMMK, str. 333-369.

15. Serajnik Sraka, N., 2008. Vrednotenje v odnosih z javnostmi. Teorija in praksa, 6/2008, str. 870-876. Fakulteta za družbene vede, Ljubljana.

16. Tepina, J., 2013. Tudi če si najmanjši, ni treba, da govoriš, kako si dober, da ljudje to prepoznajo. Revija Obramba, julij 2013, str. 12. Defensor, d. o. o.

17. Van Dyk, M., Verćič, D., 2009. Public relations, public diplomacy and strategic communication: An international model of conceptual convergence. V Sriramesh, Krishnamurty, Verčič (ured.): The global Public Relations Handbook Revised Edition: Theory, Research, and Practise, str. 822-842. London, New York.

18. Verčič, D., 1995. Odnosi z javnostmi: nastanek, zgodovina in teorije. Magistrsko delo. Fakulteta za družbene vede, Ljubljana.

19. Verčič, D., 1999. Odnosi z javnostmi v Evropi, Ljubljana. Pristop.,

20. Vuga, J., 2013. Sprejemljivost mednarodnih operacij in misij dokler ne postane »vroče«. Revija Obramba, julij 2013, str. 9. Defensor, d. o. o. 